University of Nebraska - Lincoln

DigitalCommons@University of Nebraska - Lincoln

2011

Can climate sensitivity be estimated from short-term relationships of top-of-atmosphere net radiation and surface temperature?

\author{
Bing Lin \\ NASA Langley Research Center \\ Qilong Min \\ State University of New York at Albany \\ Wenbo Sun \\ SSAI \\ Yongxiang $\mathrm{Hu}$ \\ NASA Langley Research Center \\ Tai-Fang Fan \\ SSAI
}

Follow this and additional works at: https://digitalcommons.unl.edu/nasapub

Part of the Physical Sciences and Mathematics Commons

Lin, Bing; Min, Qilong; Sun, Wenbo; Hu, Yongxiang; and Fan, Tai-Fang, "Can climate sensitivity be estimated from short-term relationships of top-of-atmosphere net radiation and surface temperature?" (2011). NASA Publications. 68.

https://digitalcommons.unl.edu/nasapub/68

This Article is brought to you for free and open access by the National Aeronautics and Space Administration at DigitalCommons@University of Nebraska - Lincoln. It has been accepted for inclusion in NASA Publications by an authorized administrator of DigitalCommons@University of Nebraska - Lincoln. 


\title{
Can climate sensitivity be estimated from short-term relationships of top-of-atmosphere net radiation and surface temperature?
}

\author{
Bing Lin ${ }^{\mathrm{a}, *}$, Qilong Min ${ }^{\mathrm{b}}$, Wenbo Sun ${ }^{\mathrm{c}}$, Yongxiang $\mathrm{Hu}^{\mathrm{a}}$, Tai-Fang Fan ${ }^{\mathrm{c}}$ \\ a NASA Langley Research Center, Hampton, VA 23681-2199, USA \\ b State University of New York at Albany, Albany, NY 12222, USA \\ ' SSAI, One Enterprise Parkway, Hampton, VA 23666, USA
}

\section{A R T I C L E I N F O}

Keywords:

Top-of-atmosphere net radiation

Climate feedback

Energy balance

\begin{abstract}
A B S T R A C T
Increasing the knowledge in climate radiative feedbacks is critical for current climate studies. This work focuses on short-term relationships between global mean surface temperature and top-of-atmosphere (TOA) net radiation. The relationships may be used to characterize the climate feedback as suggested by some recent studies. As those recent studies, an energy balance model with ocean mixed layer and both radiative and non-radiative heat sources is used here. The significant improvement of current model is that climate system memories are considered.

Based on model simulations, short-term relationship between global mean surface temperature and TOA net radiation (or the linear striation feature as suggested by previous studies) might represent climate feedbacks when the system had no memories. However, climate systems with the same short-term feedbacks but different memories would have a similar linear striation feature. This linear striation feature reflects only fast components of climate feedbacks and may not represent the total climate feedback even when the memory length of climate systems is minimal. The potential errors in the use of short-term relationships in estimations of climate sensitivity could be big. In short time scales, fast climate processes may overwhelm long-term climate feedbacks. Thus, the climate radiative feedback parameter obtained from short-term data may not provide a reliable estimate of climate sensitivity. This result also suggests that long-term observations of global surface temperature and TOA radiation are critical in the understanding of climate feedbacks and sensitivities.
\end{abstract}

Published by Elsevier Ltd.

\section{Introduction}

In the last couple of decades, the accuracy in prediction of the responses of the Earth's climate system to the increase of $\mathrm{CO}_{2}$ concentration within the atmosphere has not been significantly improved due to large climate feedback uncertainties in global climate models (GCMs). The envelope of predicted increases in global mean surface temperature for a doubled- $\mathrm{CO}_{2}\left(2 \times \mathrm{CO}_{2}\right)$

\footnotetext{
* Corresponding author. Tel.: +1 7578649823 ; fax: +1 7578647996

E-mail address: bing.lin@nasa.gov (B. Lin).
}

atmosphere is as wide as from $\sim 1.0 \mathrm{~K}$ up to more than $10 \mathrm{~K}[1]$. Shrinking the wide prediction range of climate sensitivity and/or reducing the large climate feedback uncertainties are urgent tasks for both climate sciences and socioeconomic policies, which require advanced observation, analyses and modeling of the climate system.

Most climate change projections are based on GCM simulated results. However, the extremely-complicated climatic phenomena make it impossible for GCMs to account for all major physical processes accurately. Incomplete knowledge of the processes such as those associated with clouds and precipitation causes considerable differences in their representations in 
individual GCMs, which, in turn, creates large uncertainties in projected climate changes. To improve the understanding and model performance of physical processes of the climate system, many diagnoses of climate sensitivity with both modeling and observational results have been conducted, especially on the relationships between top-of-atmosphere (TOA) radiation and surface temperature fields (e.g. [2-6]). Climate processes in various spatial and temporal scales are studied in these diagnoses, and significantly different conclusions are made. Some recent studies [7-10] even suggest to use short-term (time scale less than a decade) observational results to evaluate GCMs and to assess climate sensitivity and feedbacks.

Since a generalized approach in estimating climate feedbacks from climate records may require to consider both internal and external sources of the variability of TOA radiation as suggested by Forster and Gregory [7], Spencer and Braswell [9] simulated short-term relationship between global TOA net radiation and surface temperature based on an energy balance model with climate heat sources from certain radiative responses (feedback), internal radiative variations (non-feedback), and non-radiative (internal) heating components. Internal heating sources are needed in the simulation because only mixed layer of oceans is considered in the model and there are significant vertical heat transports between the mixed layer and deep oceans. Also, energy conversion among different heat forms, such as radiative energy and latent heat, is common in the climate system. From their simulation, Spencer and Braswell found climate sensitivities established from the statistics of average values of TOA net radiation and surface temperature as done by most observational analyses were significantly different from the 'true' sensitivities specified in their model, and claimed that potential positive biases could exist in most of current observational diagnoses of climate feedbacks including cloud and possible other feedbacks. To further their study on the climate sensitivity using their model simulations and satellite Cloud and the Earth's Radiant Energy System (CERES) observations, Spencer and Braswell [11] (hereafter SB09) noticed both spiral characteristics and linear striation features of certain branches of spirals in climatic phase space (or the relationship between TOA net radiation and surface temperature). The time scales of those linear features were much shorter than those of the whole simulated results or observed data. Because of the consistency between the slopes of the linear striations in simulated results and the modelspecified climate sensitivity, they argued that those short-term relationships between TOA net radiation and surface temperature might reflect the real climate sensitivity. Based on their theory and CERES measurements, they estimated that the climate system has a low sensitivity with a strong negative feedback parameter around $-6 \mathrm{~W} / \mathrm{m}^{2} / \mathrm{K}$. With this negative feedback parameter, the predicted global warming for $2 \times \mathrm{CO}_{2}$ atmosphere $\left(3.7 \mathrm{~W} / \mathrm{m}^{2}\right.$ forcing) would be about $0.6 \mathrm{~K}$, much less than most model predictions and even falling out of the envelop of IPCC future climate projections of various GCMs.

The use of short-term data to determine climate sensitivity related to processes of much longer time scales such as those for $2 \times \mathrm{CO}_{2}$ atmosphere is considerably different from most of previous climate studies. One concern is that short-term data may not clearly show long-term variability and feedbacks, and lead significant errors in the diagnosed climate sensitivity. Indeed, shortterm linear striations in the phase space could mislead the general climate feedback features as demonstrated by this study. The modeling and data analyzing methods used in this study are basically the same as SB09. The major difference is that a more realistic climate system with system memory is considered. As pointed out by Lin et al. [12], the actual climate system has certain memories for climate states. For example, the global mean surface temperature anomalies of the Goddard Institute for Space Studies (GISS; [13]; updated at http://data.giss.nasa.gov/ gistemp/) exhibit significant memories up to about eight years in their autocorrelation function (95\% or higher confidence level).

Next section discusses the basic energy balance model, while Section 3 presents and analyzes simulated results. The conclusion and major findings are summarized in Section 4.

\section{Methodology}

Like SB09, this study uses the energy balance model of Spencer and Braswell [9] to simulate surface temperature variations of the climate system assumed to contain only ocean mixed layer (or a shallow water model). The basic heating sources include both radiative and non-radiative components. The radiative component accounts for climate forcing, feedback and natural variability terms. The natural radiation variability term mainly involves the non-feedback natural changes in clouds and other climate variables (such as the albedos of snow caps and vegetation canopies) that affect global net radiation at different, especially interannual, time scales. This natural variability term is parameterized as a low frequency radiative heating with 5-year oscillation cycle. The non-radiative components generally represent fast climate processes such as those related to surface evaporation cooling and weather systems. Since the simulated climate system contains only a shallow water layer, some heat sources such as deep oceans would also provide certain nonradiative heating to the climate system. In current simulations, this non-radiative heating component is assumed to satisfy Gaussian random distributions with zero daily mean values. Thus, the global mean climate in a unit area [9] can be expressed as

$C p \frac{d T}{d t}=F+f_{t o t} T+N+S$

where $T$ and $t$ represent the small global mean surface temperature perturbation and the time, respectively; $C p$ is the climate heat capacity, assumed to be proportional to an effective depth $(100 \mathrm{~m})$ of the ocean mixed layer; and $F$ and $f_{\text {tot }}$ represent climate forcing term and the coefficient of total climate radiative feedbacks, respectively. Were the climate in a normal state (or zero forcing), any small temperature perturbation would cause at least a $-3.3 \mathrm{~W} / \mathrm{m}^{2} / \mathrm{K}$ of radiative heat release to space 
mainly because of blackbody emission [6]. Thus, the feedback coefficient for the normal condition $f_{n}$ is $-3.3 \mathrm{~W} / \mathrm{m}^{2} / \mathrm{K}$. For a climate, any feedback coefficient $f_{\text {tot }}$ values larger (smaller) than $f_{n}$ would be the result of positive (negative) climate feedbacks besides the blackbody thermal emission (Note: hereafter the meaning of 'positive' or 'negative' climate feedbacks is based on this blackbody emission concern). The $N$ and $S$ values represent non-radiative heating and the non-feedback natural radiative variability terms, respectively.

Since the climate system described by Eq. (1) only deals with short-time scale (including instantaneous) feedbacks and climate states, no historical climate state (or memory) is involved. Thus, we call the feedback coefficients in the equation as short-term feedback $f_{S}$. For short-time scales and small climate perturbations, the changes in surface net radiation, mainly from emission, would be radiated to space at TOA as a result of too little atmospheric heat capacity and the short time for the climate to adapt to the surface change. Thus, the climate system has a strong tendency that pushes itself back to its equilibrium state for small short-term climate perturbations by radiation adjustment. SB09 suggests that this short-term feedback coefficient should be about $-6 \mathrm{~W} / \mathrm{m}^{2} / \mathrm{K}$. This short-term feedback $f_{S}$ can be considered as a result of the normal climate feedback $f_{n}$ superimposed by fast radiative heat release processes of the climate system with a feedback coefficient $f$ of $-2.7 \mathrm{~W} / \mathrm{m}^{2} / \mathrm{K}$, i.e., $f_{S}=f_{n}+f$.

As mentioned in the introduction, the actual climate system also has certain memories for climate states. These memories may be a result of different climate physical processes such as those associated with soil moisture, frozen soil/snow/ice in cold regions, and oceanic circulations [12]. Thus, a feedback term for climate system memory $f_{m}$ is added to Eq. (1). This climate memory feedback comes from a non-instantaneous response of the climate system and has significant contributions to the climate sensitivity. In this study, we use the average of surface temperature perturbations during previous time periods to represent the effect of the climate feedbacks from memories. Thus, Eq. (1) becomes

$C p \frac{d T}{d t}=F+f_{S} T+N+S+\frac{f_{m}}{t_{m}} \int_{t-t m}^{t} T d t^{\prime}$,

where $t_{m}$ is the system memory length. When memory length $t_{m}$ approaches zero, the memory term reduces to $f_{m} T$, which can be merged to the short-term feedback $f_{S} T$ term, i.e., the system has no memory effects. In this case, our analysis is converged to previous SB09 studies.

Even though Eq. (2) is not in a normal form of linear different equation (LDE), the total feedback coefficient of the climate system can be obtained in a manner similar to a linear equation. For an example, for a forced climate with forcing $F$, the asymptotic solution provides: $T(t \rightarrow$ $\infty)=-F(t \rightarrow \infty) /\left(f_{S}+f_{m}\right)=-F(t \rightarrow \infty) / f_{\text {tot }}$, where the total feedback $f_{\text {tot }}$ is the combined result of $f_{S}$ and $f_{m}$.

\section{Results}

Since the main goal of this study is to assess the feasibility in the use of relationships between TOA radiation and surface temperature to estimate climate sensitivity, the normal climate state is considered in the simulations, following SB09. Thus, the forcing term $F$ (e.g., anthropogenic radiative forcing) is assumed to be either zero or known and removed. The key part of this study is to simulate the climate with and without the memory and to highlight the potential difficulties in the use of only short-term data in estimations of climate sensitivity.

Variations of global 90-day running means of surface temperature perturbation with climate radiative heating sources for a simulated climate system (Eq. (2)) without memories are shown in Fig. 1. The simulation has run for 100 years, and only the last 10 years of the results are plotted here. Ten-year simulated results are used because the record lengths of most analyzed observational data from major satellite TOA broadband radiation measurements such as those from the Earth Radiation Budget Experiment (ERBE) and CERES are generally within a decade. In this simulation, the short-term feedback coefficient $f_{S}$ is set to be $-6 \mathrm{~W} / \mathrm{m}^{2} / \mathrm{K}$ as suggested by SB09 and mentioned in previous sections. Current simulated results for this no-memory case are basically the same as those obtained by SB09, and thus served as the baseline in the diagnosis of climate radiative feedbacks.

As shown in the figure, corresponding to individual TOA net radiation values, there could be multiple surface temperatures, which reflect the chaotic nature of the climate system that even with similar net radiation heating to the system, the system still can have significantly different internal heat sources and development processes, resulting in different states. Spiral characteristics of the climate system in its phase space shown in Fig. 1 mainly represent the basic climate variability of surface temperature and TOA net radiation and the tendency of the system to restore its equilibrium state after certain perturbations. It can be seen that the statistically-averaged relationship of surface temperature and TOA net radiation would be much less than that of model specified climate feedback $\left(-6 \mathrm{~W} / \mathrm{m}^{2} / \mathrm{K}\right)$. However, the linear striations in certain branches of the spirals in current case could exhibit the climate radiative feedback feature specified in the model. The question is if these

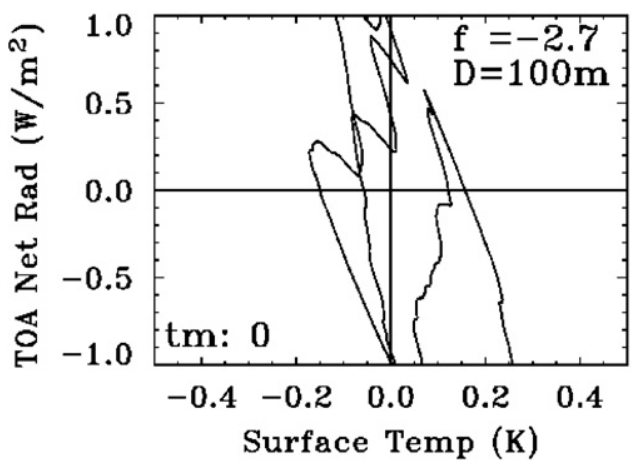

Fig. 1. Simulate relationship between global mean surface temperature and TOA net radiation for a climate system without any memories under normal climate states. The short-term radiative feedback $\left(f_{S}=f_{n}+f\right)$ is set to be $-6 \mathrm{~W} / \mathrm{m}^{2} / \mathrm{K}$, i.e., the $f$ parameter for fast heat release processes is assumed to be $-2.7 \mathrm{~W} / \mathrm{m}^{2} / \mathrm{K}$ (c.f. the text). 
linear striations can be considered as the general feature in estimations of climate feedbacks.

Figs. 2-4 plot the same simulations as that of Fig. 1 except climate system memories are concerned. In these plots, the memory length $t_{m}$ of the climate system is set to be one year. From GISS global surface temperature measurements, Lin et al. [12] estimated that the climate system has at least about eight years of memories. The reason of one-year memory used in this study is to show

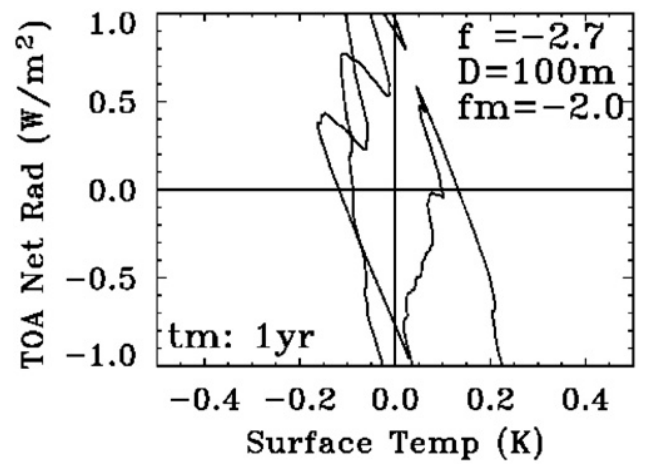

Fig. 2. Same as Fig. 1, except that the radiative feedback from climate system memories with a feedback coefficient $f_{m}-2.0 \mathrm{~W} / \mathrm{m}^{2} / \mathrm{K}$ and memory length $t_{m} 1$ year is concerned.

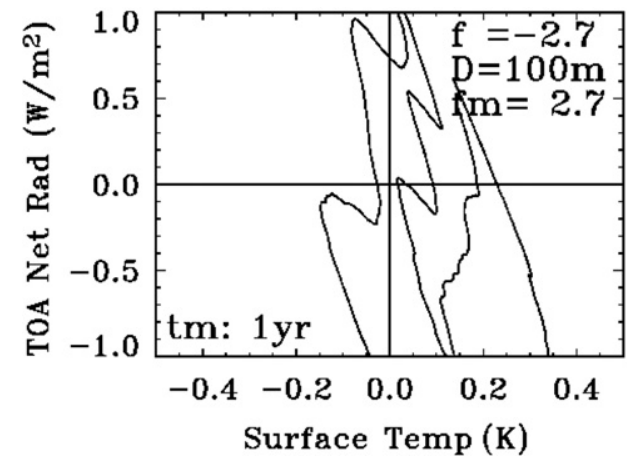

Fig. 3. Same as Fig. 2, except that the feedback coefficient for system memories $f_{m}$ is set to be $2.7 \mathrm{~W} / \mathrm{m}^{2} / \mathrm{K}$.

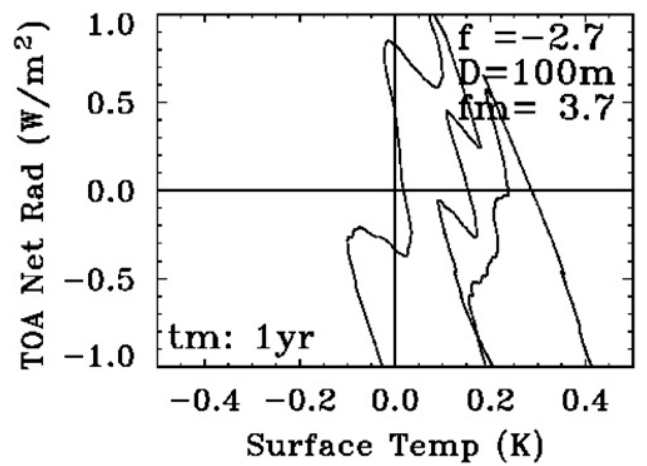

Fig. 4. Same as Fig. 2, except that the feedback coefficient for system memories $f_{m}$ is set to be $3.7 \mathrm{~W} / \mathrm{m}^{2} / \mathrm{K}$. that climate feedbacks do not fully exhibit in the shortterm relationship (or the linear striations) between surface temperature and TOA net radiation even for a climate system with a minimal length of memory. The radiative feedback coefficient $f_{m}$ for the climate system memories in Figs. $2-4$ is $-2.0,2.7$ and $3.7 \mathrm{~W} / \mathrm{m}^{2} / \mathrm{K}$, respectively. These radiative feedbacks represent climate systems with total radiative feedbacks varying from very negative $\left(f_{\text {tot }}=-8.0 \mathrm{~W} / \mathrm{m}^{2} / \mathrm{K}\right)$, neutral (or blackbody emission, $\left.f_{\text {tot }}=-3.3 \mathrm{~W} / \mathrm{m}^{2} / \mathrm{K}\right)$, to slightly positive $\left(f_{\text {tot }}=-2.3 \mathrm{~W} / \mathrm{m}^{2} / \mathrm{K}\right)$ conditions, respectively. It can be seen that climate systems with memories still have significant spiral characteristics and linear striation features as the systems without memories. Furthermore, the slopes of linear striation in all Figs. 1-4 are very similar and close to the specified short-term feedback coefficient $f_{S}\left(-6.0 \mathrm{~W} / \mathrm{m}^{2} / \mathrm{K}\right)$ in the model. This result reflects the short-term (or fast) climate radiative responses to surface temperature variations or the tendency of climate system to reach its equilibrium state in short-time scales. During a short time period, there could be significant global surface temperature fluctuations. But the averaged temperature change during this period should be small. Thus, long-term feedbacks would be significantly weaker compared to short-term feedbacks during this period and cannot be detected by short-term observations.

The difference among Figs. $1-4$ is the phase space occupied by the relationships of surface temperature and TOA net radiation. As expected the stronger the total negative feedbacks, the narrower the surface temperature and the wider the TOA radiation variations are. Compared to the results shown in Figs. 2-4, the simulated spiral and striation features for climate systems with longer memories (not shown here) are even closer to those without memory case. The longer the memory or the feedback processes, the weaker the signals may exhibit in short time scales.

These simulated results demonstrate that the linear striations in phase space may not reflect true radiative feedbacks of the climate system for a climate system with certain memories. Long-term observed and model data are critical for climate feedback diagnoses. The analysis of only short-term variations could lead significant errors in estimations of climate sensitivity.

\section{Conclusions}

Increasing knowledge of climate radiative feedbacks and reducing uncertainties of climate sensitivity is critical for climate studies. This work focuses on the short-term relationships between global mean surface temperature and TOA net radiation (or the linear striation features in phase space) that may represent actual climate feedback characteristics as suggested by some recent studies. Current study uses basically the same energy balance model as SB09. The significant difference between current analysis and previous energy balance models is that climate system memories are considered because the actual climate system has certain memories for its states as exhibited in the measurements of global mean surface temperature. 
Based on the simulated results of the energy balance model, certain branches in spirals of the relationship between global mean surface temperature and TOA net radiation might represent climate feedbacks when the system had no any memories. However, climate systems with the same short-term feedbacks but different memories would have similar linear striation features. These linear striation features reflect only the fast response part of climate feedbacks and do not represent the total climate feedback even when the system memory length is minimal. The potential errors in the use of shortterm relationships of global mean surface temperature and TOA net radiation in estimations of climate sensitivity could be big. In short time scales, fast climate processes may overwhelm long-term response of the climate system introduced by its memories. Thus, the $-6.0 \mathrm{~W} / \mathrm{m}^{2} / \mathrm{K}$ climate radiative feedback parameter estimated from CERES short-term measurements might not be considered as the total feedback parameter, and its predicted corresponding $0.6 \mathrm{~K}$ potential warming for the $2 \times \mathrm{CO}_{2}$ atmosphere $\left(3.7 \mathrm{~W} / \mathrm{m}^{2}\right.$ forcing) may not be reliable. More importantly, as discussed in [12], climate feedbacks and sensitivities strongly depend on time scales. Different time scales have different inherent climate physical, chemical and biological processes and thus, could have different memories, feedbacks and sensitivities. The climate feedbacks and sensitivities observed at one time scale generally cannot represent climate processes at other time scales. These results also suggest that long-term observations of global surface temperature and TOA radiation are critical in the understandings of climate feedbacks and sensitivities.

\section{Acknowledgements}

The authors would like to express their appreciation to T. Wong, G. Gibson, N. Loeb, L. Chambers, D. Young, and D. Garber for their valuable comments and encouragement. This research was supported by NASA
CERES mission and Energy and Water cycle Studies (NEWS) program

\section{References}

[1] IPCC. Summary for policymakers. In: Solomon, S, Qin D, Manning M, Chen Z, Marquis M, Averyt KB, Tignor M, Miller HL, editors. Climate change 2007: the physical science basis. Contribution of working group I to the fourth assessment report of the intergovernmental panel on climate change. Cambridge, United Kingdom and New York, USA: Cambridge University Press; 2007.

[2] Hansen J, Lacis A, Rind D, Russell G, Stone P, FungI, et al. Climate sensitivity: analysis of feedback mechanisms. In: Hansen JE, Takahashi T, editors. Climate processes and climate sensitivity, AGU geophysical monograph 29, Maurice Ewing, vol. 5. American Geophysical Union, < http://pubs.giss.nasa.gov/docs/1984/1984 Hansen_etal_1.pdf > ; 1984. p. 130-63.

[3] Manabe S, Bryan K, Spelman M. Transient response of a global ocean-atmosphere model to a doubling of atmospheric carbon dioxide. J Phys Ocean 1990;20:722-49.

[4] Lin B, Wielicki B, Chambers L, Hu Y, Xu K-M. The iris hypothesis: a negative or positive cloud feedback?J Clim 2002;15:3-7

[5] Lin B, Wielicki BA, Minnis P, Chambers L, Xu K-M, Hu Y, et al. The effect of environmental conditions on tropical deep convective systems observed from the TRMM satellite. J Clim 2006;19:5745-61.

[6] Forster P, Taylor K. The climate forcings and climate sensitivities diagnosed from coupled climate model integrations. J Clim 2006;19:6181-94.

[7] Forster P, Gregory J. The climate sensitivity and its components diagnosed from earth radiation budget data. J Clim 2006;19:39-52.

[8] Spencer RW, Braswell WD, Christy JR, Hnilo J. Cloud and radiation budget changes associated with tropical intraseasonal oscillations. Geophys Res Lett 2007;34:L15707, doi:10.1029/2007GL029698.

[9] Spencer R, Braswell W. Potential biases in feedback diagnosis from observational data: a simple model demonstration. J Clim 2008;21: 5624-8.

[10] Lindzen R, Choi Y-S. On the determination of climate feedbacks from ERBE data. Geophys Res Lett 2009;36:L16705, doi:10.1029/ 2009GL039628.

[11] Spencer R, Braswell W. On the diagnosis of radiative feedback in the presence of unknown radiative forcing. In: Proceedings of the fall meeting of American geophysics union, San Francisco, CA; December 14-18, 2009 (can also be found: http://www.drroyspen cer.com/research-articles/satellite-and-climate-model-evidence/ or http://science.larc.nasa.gov/ceres/STM/2009-04/pdf/14_Forcingfeedback-2-CERES-April-2009_Spencer.pdf).

[12] Lin B, Chambers L, Stackhouse P, Wielicki B, Hu Y, Minnis P, et al. Estimations of climate sensitivity based on top-of-atmosphere radiation imbalance. Atmos Chem Phys 2010;10:1923-30.

[13] Hansen J, Ruedy R, Sato M, Reynolds R. Global surface air temperature in 1995: return to pre-Pinatubo level. Geophys Res Lett. $1996 ; 23: 1665-8$. 